\title{
Sensitivity analysis of a smooth muscle cell electrophysiological model.
}

\author{
Sanjay R. Kharche ${ }^{1,2}$, Galina Yu. Mironova ${ }^{3}$, Daniel Goldman², Christopher W. \\ McIntyre ${ }^{1}$, and Donald G. Welsh ${ }^{3}$. \\ ${ }^{1}$ Lawson Health Research Institute, London, Canada. N6A 5W9. \\ ${ }^{2}$ Department of Medical Biophysics, Western University, London, Canada. N6A 5C1. \\ ${ }^{3}$ Robarts Research Institute, Western University, London, Canada. N6A 5C1. \\ Sanjay.Kharchedlhsc.on.ca
}

\begin{abstract}
Cardiac smooth muscle cell mathematical models are increasingly being used in clinical decision making and drug testing. The cell models also have the potential to assist interpretation and extending of our multi-scale experimental findings. Components of the models interact with each other to regulate model behavior in a non-linear manner. To permit meaningful deployment of the models, it is therefore a necessity to understand the regulatory significance of model components' parameters on the model's behavior. In this study, the regulation of mean intra-cellular calcium and mean membrane potential (model behavior) by underlying model parameters (regulators) in a smooth muscle cell mathematical model was quantified using two sensitivity analysis methods. It was found that extracellular electrolytes and gating kinetics are prime model behavior regulators. A representative case relevant to widespread hypertension focusing on the L-type channel's parameters is presented. This sensitivity analysis will guide our future data driven modelling efforts.
\end{abstract}

Keywords: Smooth muscle cell, mathematical model, coronary vasculature, sensitivity analysis.

\section{Introduction.}

Electrically active building blocks of blood vessels called smooth muscle cells (SMCs) effect vascular tone $[1,2]$ in arteries, including those in cardiac walls (coronary arteries). We think that debilitating conditions such as hypertension and renal failure alter L-type calcium ion channel ( $\mathrm{I}_{\mathrm{CaL}}$ ) function and promote accumulation of intracellular calcium $\left(\left[\mathrm{Ca}^{2+}\right]_{i}\right)$ in SMCs [3]. In accordance with experimental protocols, SMC model behavior is characterized by $\left[\mathrm{Ca}^{2+}\right]_{\mathrm{i}}$ and membrane potential, $\mathrm{V}_{\mathrm{m}}$. An understanding of how $\mathrm{I}_{\mathrm{CaL}}$ parameters regulate SMC mathematical model behavior will guide our future experimental-modelling investigations.

In multiple SMC modelling studies, the regulation of model behavior by either maximal transport rates and conductances $[4,5]$ or biochemical availability [6] has previously been demonstrated. However, it can be appreciated that other modelling parameters also play a vital role in model behavior (see Fig. 1). We have previously observed 
that the inherently coupled nature of mathematical model components (e.g. ion channel gating and intracellular $\left[\mathrm{Ca}^{2+}\right]_{i}$ processes) necessitates the inclusion of all model parameters in meaningful sensitivity analysis [7]. In silico studies should take into account multiple modelling parameters in light of experimental findings where $\left[\mathrm{Ca}^{2+}\right]_{\mathrm{i}}$ increase has been attributed to both an augmented ion channel expression density [8] as well as altered ion channel gating pathways independently of conductance alterations [9].

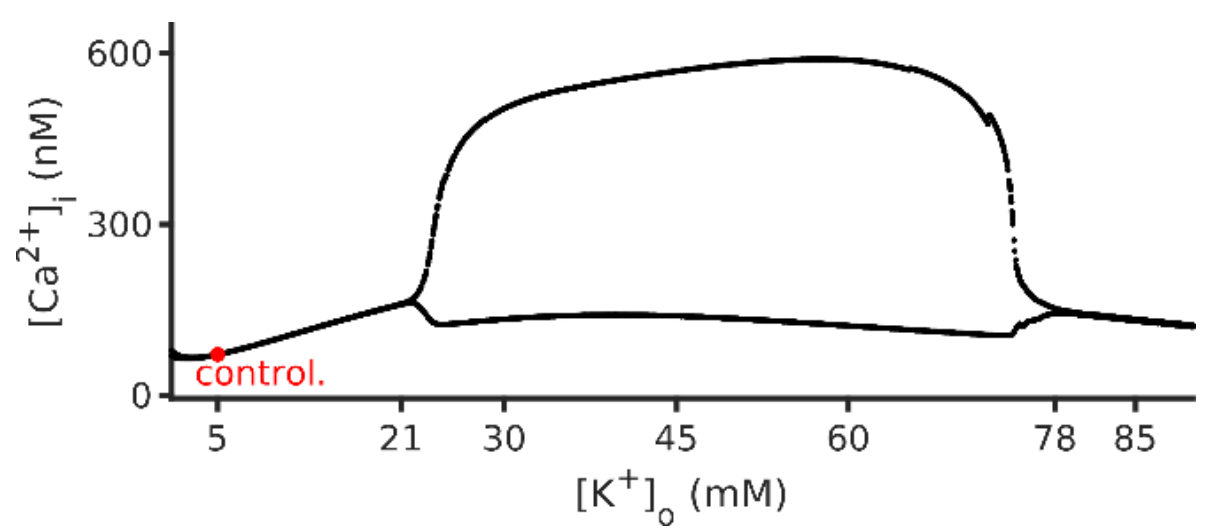

Fig. 1. Bifurcation diagram illustrating regulation of $\left[\mathrm{Ca}^{2+}\right]_{i}$ dynamics by extracellular potassium, $\left[\mathrm{K}^{+}\right]_{\mathrm{o}}$. For low concentrations of $\left[\mathrm{K}^{+}\right]_{\mathrm{o}}$ (less than $21 \mathrm{mM}$ ), the SMC model generated a steady state $\left[\mathrm{Ca}^{2+}\right]_{i}$. For larger values of $\left[\mathrm{K}^{+}\right]_{\mathrm{o}}(21 \mathrm{mM}$ to $78 \mathrm{mM}),\left[\mathrm{Ca}^{2+}\right]_{\mathrm{i}}$ oscillations were observed.

In this preliminary work, an established smooth muscle cell model [4] was used to rank the regulatory impact of all parameters in a SMC model [4] on its mean intracellular $\left[\mathrm{Ca}^{2+}\right]_{\mathrm{i}}$ and mean membrane potential, $\mathrm{V}_{\mathrm{m}}$. To do so, two sensitivity analysis methods $[7,10]$ were adopted. As a case of interest, findings focused on $\mathrm{I}_{\mathrm{CaL}}$ and related parameters are presented.

\section{Methods.}

The smooth muscle cell, SMC, model [4] adopted in this work is a system of 27 coupled ordinary differential equations. The model computer program was obtained from CellML repository [11] and programmed into our robust ordinary differential equations solver based on an advanced external library [12]. The model has 48 parameters that consist of all conductance values, maximum transport fluxes, steady state gating parameters, time constant scaling factors, extracellular electrolyte concentrations, and the capacitance. Parameters' descriptions, acronyms, and their control values relevant to this work are provided in Table 1. Model behavior was defined as mean values of $\left[\mathrm{Ca}^{2+}\right]_{\mathrm{i}}$ and membrane potential, $\mathrm{V}_{\mathrm{m}}$.

To permit sensitivity analysis, a control model population of $10^{4}$ instances was constructed. To generate the population, 48 modelling parameter were each sampled simultaneously from Gaussian distributions using a non-repetitive Mersenne Twister ran- 
dom number generator [13], with sampling constrained using Latin Hypercube Sampling [14]. The mean values in each parameter's Gaussian distribution was obtained from the original model [4], while a coefficient of variation of 1.5 was adopted. The adopted coefficient of variation provided a large $( \pm 100 \%)$ range sampling for each parameter. A model instance in the population was defined by one sampling, and was used in the model to generate mean $\left[\mathrm{Ca}^{2+}\right]_{\mathrm{i}}$ and $\mathrm{V}_{\mathrm{m}}$. Each model instance required $9.5 \mathrm{~s}$ to generate 100 seconds of simulated activity on one Linux processor. The population of $10^{4}$ models was generated using 128 processors within four hours using open source GNU tools. In addition to the control population, a second population where cell capacitance was reduced to $15 \mathrm{pF}$ was also generated. The model parameters and model outputs were stored and further processed using two sensitivity analysis methods.

Table 1. Relevant model parameters.

\section{Parameter.}

\section{Description.}

Control value.

Extracellular electrolytes and capacitance.

\begin{tabular}{|c|c|c|}
\hline$\left[\mathrm{Ca}^{2+}\right]_{0}$ & Calcium. & $2 \mathrm{mM}$. \\
\hline$\left[\mathrm{Na}^{+}\right]_{\mathrm{o}}$ & Sodium. & $140 \mathrm{mM}$. \\
\hline$\left[\mathrm{K}^{+}\right]_{\mathrm{o}}$ & Potassium. & $5 \mathrm{mM}$ \\
\hline$\left[\mathrm{Cl}^{-}\right]_{\mathrm{o}}$ & Chlorine. & $129 \mathrm{mM}$. \\
\hline \multirow[t]{2}{*}{$\mathrm{C}_{\mathrm{m}}$} & Cell capacitance. & $25 \mathrm{pF}$. \\
\hline & Membrane current conductance values. & \\
\hline $\mathrm{P}$ & L-type calcium channel conductance. & $1.88 \times 10^{-5} \mathrm{~cm} / \mathrm{s}$ \\
\hline \multirow[t]{2}{*}{$\mathrm{g}_{\mathrm{K}}$} & $\begin{array}{l}\text { Delayed rectifier potassium channel conduct- } \\
\text { ance. }\end{array}$ & $1.35 \mathrm{nS}$. \\
\hline & Intra-cellular calcium release/uptake. & \\
\hline ISERCA & $\begin{array}{c}\text { Maximum }\left[\mathrm{Ca}^{2+}\right]_{\mathrm{i}} \text { uptake by sarcoplasmic re- } \\
\text { ticulum (SR). }\end{array}$ & $6.68 \mathrm{pA}$. \\
\hline \multirow[t]{2}{*}{$\mathrm{K}_{\text {leak }}$} & SR $\left[\mathrm{Ca}^{2+}\right]_{\mathrm{i}}$ leak parameter. & $1.07 \times 10^{-7}$ (unitless). \\
\hline & L-type calcium channel gating. & \\
\hline$\tau_{\mathrm{a}}$ & Time constant of activation. & Seconds. (fast). \\
\hline$\tau_{\mathrm{i}}$ & Time constant of inactivation. & Seconds (slow). \\
\hline $\mathrm{V}_{1 / 2, \mathrm{a}}$ & Half voltage of steady state activation. & $0 \mathrm{mV}$ \\
\hline $\mathrm{V}_{1 / 2, \mathrm{i}}$ & Half voltage of steady state inactivation. & $-42 \mathrm{mV}$ \\
\hline $\mathrm{k}_{\mathrm{a}}$ & Slope of steady state activation. & $8.3 \mathrm{mV}$. \\
\hline $\mathrm{k}_{\mathrm{i}}$ & Slope of steady state inactivation. & $9.1 \mathrm{mV}$. \\
\hline
\end{tabular}

Sensitivity analysis which ranked parameters according to their impact on model behavior was performed using partial rank correlation coefficients (PRCC) [10] as well as mutual information [7]. Briefly, PRCC performs partial correlation on rank transformed data. The data's rank transformation is used to construct PRCC, and is distinct from sensitivity analysis generated parameter ranking. PRCC assumes a linear underlying statistical model (regression) as well as monotonicity to provide the strength of 
the linear relationship between a given pair of parameter and model behaviour (output) $[10,15]$, which are $\left[\mathrm{Ca}^{2+}\right]_{i}$ or $\mathrm{V}_{\mathrm{m}}$ in the present study. The range of PRCC is from -1 to +1 by its mathematical definition. Information theoretic motivated mutual information index $[16,17]$ provides a measure of the amount of mutual dependence of a given parameter on a chosen model output. Normalization of the mutual information index provides a normalized mutual information index (NMII), which permits comparison across parameters and populations. The NMII ranges between 0 and +1 when mutual information is computed in bits.

Whereas the sensitivity analysis considered all model parameters (48 in total), Table 1 provides the 15 parameters whose sensitivities are presented in this study.

\section{Results.}

As illustrated in Fig. 2, the maximal intracellular calcium $\left(\left[\mathrm{Ca}^{2+}\right]_{\mathrm{i}}\right)$ PRCC values belong to extracellular calcium, cell capacitance, and $\mathrm{I}_{\mathrm{CaL}}$ activation gate parameter, $\mathrm{k}_{\mathrm{a}}$. The $I_{C a L}$ gating parameters, $\mathrm{V}_{1 / 2, \mathrm{a}}$ and $\mathrm{V}_{1 / 2, \text { in }}$, have larger numerical values of $\left[\mathrm{Ca}^{2+}\right]_{\mathrm{i}}$ PRCC, in comparison to the conductances, $\mathrm{P}$ and $\mathrm{g}_{\mathrm{K}}$. $\left[\mathrm{Ca}^{2+}\right]_{\mathrm{i}}$ transport rates, represented by $\mathrm{I}_{\mathrm{SERCA}}$ and $\mathrm{K}_{\text {leak }}$, have a low intracellular PRCC ranking.

The maximal membrane potential $\left(\mathrm{V}_{\mathrm{m}}\right)$ PRCC values belong to extracellular chloride, sodium, as well as cell capacitance. The $\mathrm{I}_{\mathrm{CaL}}$ gating parameters, $\tau_{\mathrm{a}}$ and $\tau_{\mathrm{i}}$, are ranked higher than the $\mathrm{I}_{\mathrm{CaL}}$ conductance by the PRCC sensitivity analysis. The $\left[\mathrm{Ca}^{2+}\right]_{i}$ transport processes were seen to have minimal ranking. The PRCC ranking of the potassium conductance, $\mathrm{g}_{\mathrm{K}}$, is higher for membrane potential as compared to intra-cellular calcium. Reduction of capacitance altered the numerical values of PRCCs, but rankings were largely unaffected. 

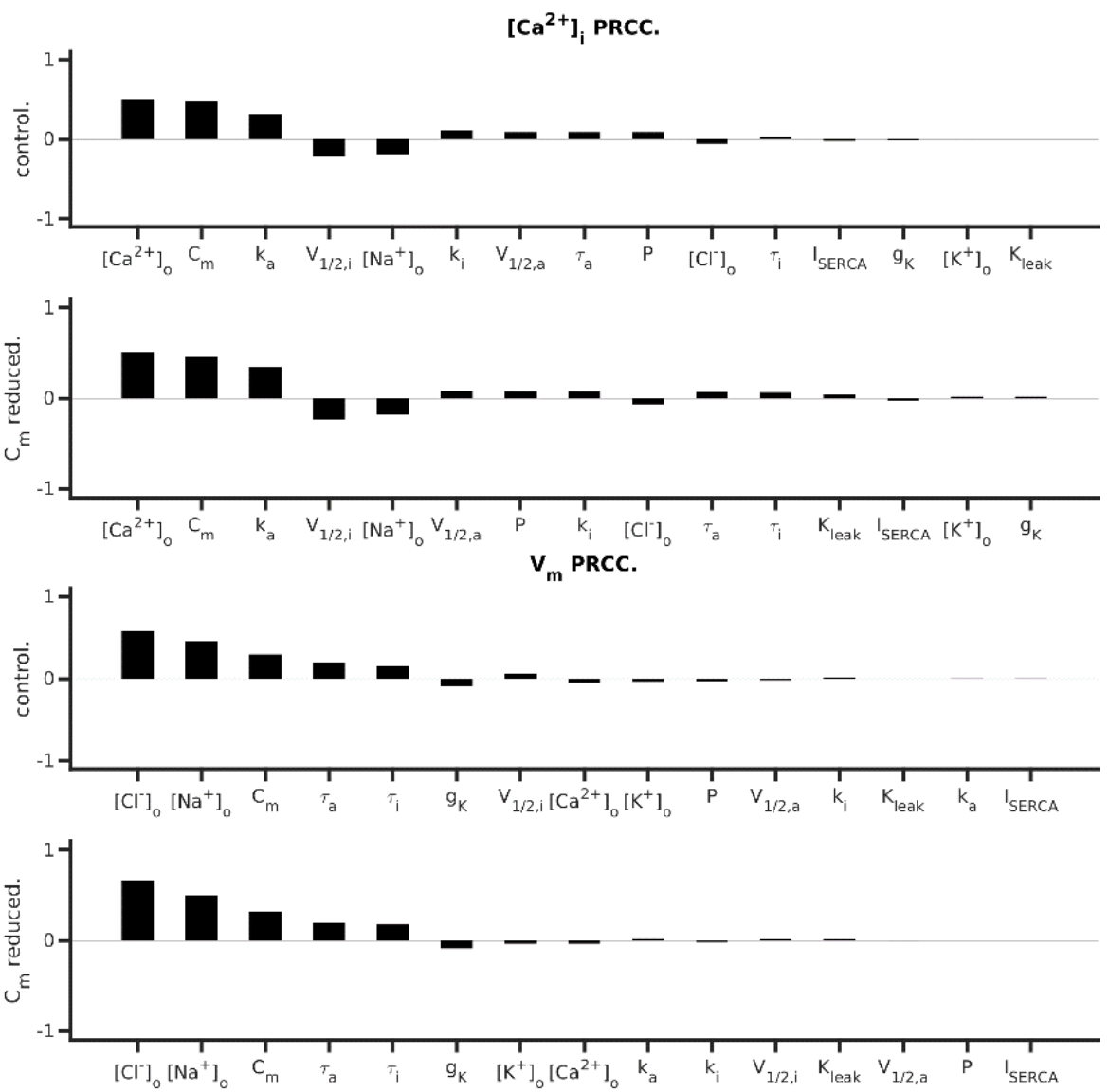

Fig 2. PRCCs for intracellular calcium $\left(\left[\mathrm{Ca}^{2+}\right] \mathrm{i}\right.$, top two panels) and membrane potential $\left(\mathrm{V}_{\mathrm{m}}\right.$, bottom two panels) each under control and reduced capacitance $\left(\mathrm{C}_{\mathrm{m}}\right.$ reduced $)$ conditions. Symbols are described in Table $\mathbf{1}$.

Normalized mutual information indices (NMIIs) (Fig. 3) show that model behavior (i.e. both $\left[\mathrm{Ca}^{2+}\right]_{\mathrm{i}}$ and $\mathrm{V}_{\mathrm{m}}$ ) depend maximally on extracellular sodium, potassium, $\mathrm{I}_{\mathrm{CaL}}$ inactivation gating parameters $\left(\tau_{\mathrm{i}}\right.$ and $\left.\mathrm{V}_{1 / 2, \mathrm{i}}\right)$, and capacitance. NMIIs ranked all $\mathrm{I}_{\mathrm{CaL}}$ gating parameters higher than ion channel conductances. Among intracellular calcium

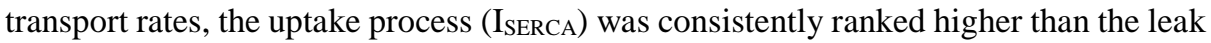
process, regulated by parameter $\mathrm{K}_{\text {leak }}$. Similar to PRCC, reduction of capacitance altered NMII numerically, but rankings were largely unaffected. 

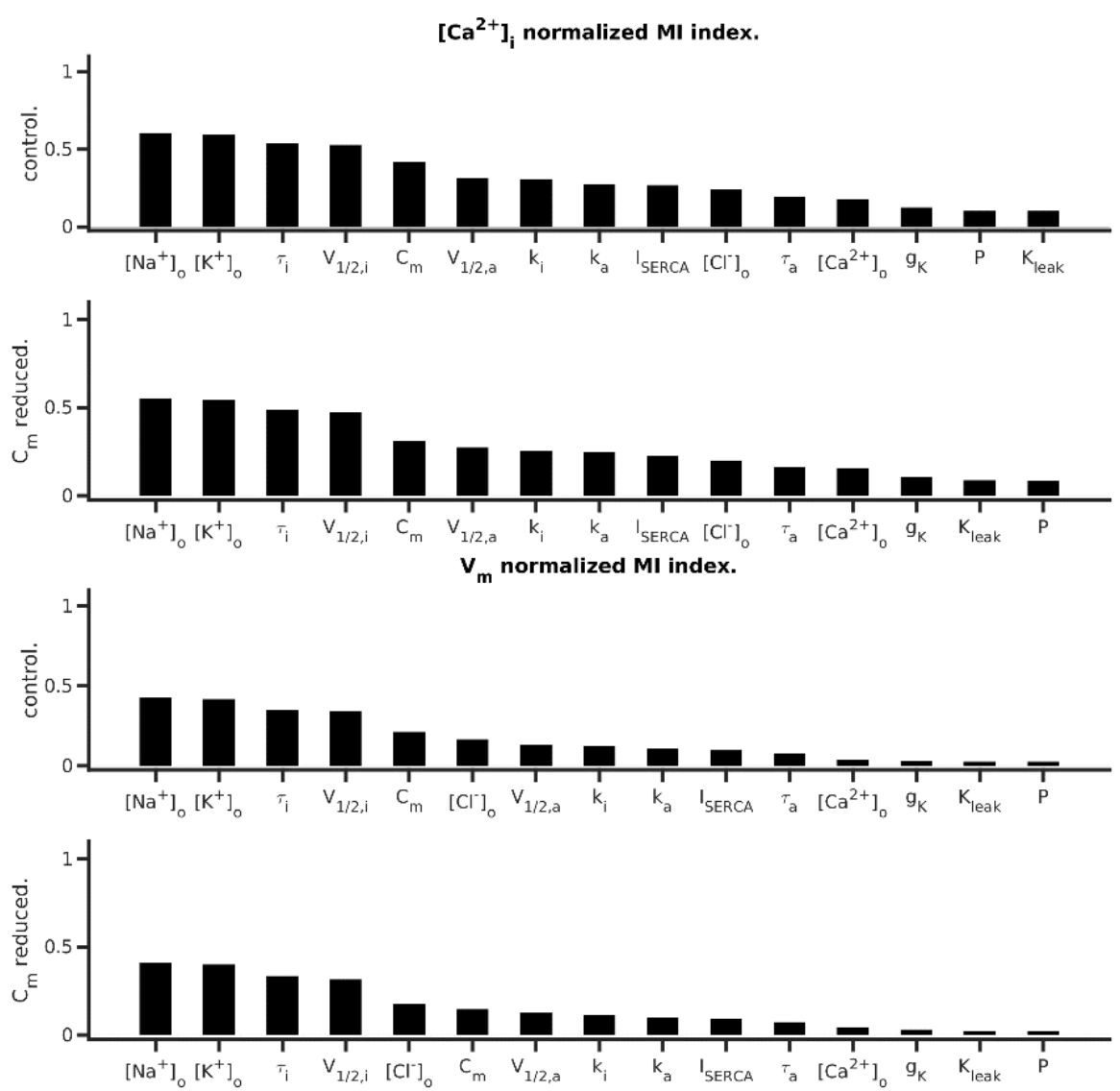

Fig. 3. NMII for intracellular calcium $\left(\left[\mathrm{Ca}^{2+}\right]_{\mathrm{i}}\right.$, top two panels) and membrane potential $\left(\mathrm{V}_{\mathrm{m}}\right.$, bottom two panels) under control and reduced capacitance $\left(\mathrm{C}_{\mathrm{m}}\right.$ reduced $)$ conditions. Symbols are described in Table 1.

\section{Conclusions and Discussion.}

Both sensitivity analysis measures, PRCC as well as NMII, suggest that the prime regulators of model $\left[\mathrm{Ca}^{2+}\right]_{i}$ are electrolytes and cell capacitance rather than calcium induced calcium release processes, which is in line with experimental protocols that use external biochemical and biophysical stimulation to study $\left[\mathrm{Ca}^{2+}\right]_{\mathrm{i}}$ dynamics $[1,18]$. In addition, both analyses demonstrated that ion channel gating processes supersede conductance in their impacts on $\left[\mathrm{Ca}^{2+}\right]_{\mathrm{i}}$ and $\mathrm{V}_{\mathrm{m}}$, which is also aligned with experimental findings related to $\mathrm{I}_{\mathrm{CaL}}$ alterations under hypertension [9]. The SMC model used in this study [4], similar to several cardiac models [19-21], rely upon a membrane $\mathrm{I}_{\mathrm{CaL}}$ calcium induced sarcoplasmic calcium release mechanism to represent $\left[\mathrm{Ca}^{2+}\right]_{i}$ dynamics. The higher impact of $\mathrm{I}_{\mathrm{CaL}}$ in comparison to intracellular calcium transporter processes was reflected by both, PRCC and NMII. 
PRCC and NMII provide very different insights regarding model properties. The partial regression based coefficients (PRCC) provide a quantitative manner in which model parameters can be estimated in relation to experimental data using appropriate methods [22]. It can be appreciated that PRCC based parameter estimation is likely to be in the vicinity of the baseline model, after which new PRCC values are required. On the other hand, mutual information provides a quantitative index providing co-dependence information. The measurement of model behaviour is likely to provide information regarding the highly ranked parameters. As such, disease conditions are known the affect model parameters, and the two methods used in this preliminary work offer a reliable approach to guide our modelling efforts.

\section{Acknowledgements.}

This work was supported by Canarie Inc. (RS3-111, CWM, DG, SRK), Canadian Heart and Stroke funding (G-20-0028717, CWM) and (R4081A03, DG). SRK thanks Compute Canada for HPC resources. All authors approved the manuscript.

\section{References.}

[1] Abd El-Rahman, R.R., Harraz, O.F., Brett, S.E., Anfinogenova, Y., Mufti, R.E., Goldman, D., Welsh, D.G.: Identification of L- and T-type Ca2+ channels in rat cerebral arteries: role in myogenic tone development. Am J Physiol Heart Circ Physiol 304, H58-71 (2013)

[2] Hansen, P.B., Poulsen, C.B., Walter, S., Marcussen, N., Cribbs, L.L., Skott, O., Jensen, B.L.: Functional importance of $\mathrm{L}$ - and $\mathrm{P} / \mathrm{Q}$-type voltage-gated calcium channels in human renal vasculature. Hypertension 58, 464-470 (2011)

[3] Navedo, M.F., Cheng, E.P., Yuan, C., Votaw, S., Molkentin, J.D., Scott, J.D., Santana, L.F.: Increased coupled gating of L-type $\mathrm{Ca} 2+$ channels during hypertension and Timothy syndrome. Circ Res 106, 748-756 (2010)

[4] Kapela, A., Bezerianos, A., Tsoukias, N.M.: A mathematical model of Ca2+ dynamics in rat mesenteric smooth muscle cell: agonist and NO stimulation. J Theor Biol 253, 238-260 (2008)

[5] Morotti, S., Nieves-Cintron, M., Nystoriak, M.A., Navedo, M.F., Grandi, E.: Predominant contribution of L-type Cav1.2 channel stimulation to impaired intracellular calcium and cerebral artery vasoconstriction in diabetic hyperglycemia. Channels (Austin) 11, 340-346 (2017)

[6] Jacobsen, J.C., Aalkjaer, C., Nilsson, H., Matchkov, V.V., Freiberg, J., Holstein-Rathlou, N.H.: A model of smooth muscle cell synchronization in the arterial wall. Am J Physiol Heart Circ Physiol 293, H229-237 (2007)

[7] Kharche, S., Ludtke, N., Panzeri, S., Zhang, H.: A Global Sensitivity Index for Biophysically Detailed Cardiac Cell Models: A Computational Approach. LNCS 5528, 10 (2009)

[8] Pratt, P.F., Bonnet, S., Ludwig, L.M., Bonnet, P., Rusch, N.J.: Upregulation of L-type Ca2+ channels in mesenteric and skeletal arteries of SHR. Hypertension 40, 214-219 (2002)

[9] Ghosh, D., Nieves-Cintron, M., Tajada, S., Brust-Mascher, I., Horne, M.C., Hell, J.W., Dixon, R.E., Santana, L.F., Navedo, M.F.: Dynamic L-type CaV1.2 channel trafficking facilitates $\mathrm{CaV} 1.2$ clustering and cooperative gating. Biochimica et biophysica acta. Molecular cell research $1865,1341-1355$ (2018) 
[10] Marino, S., Hogue, I.B., Ray, C.J., Kirschner, D.E.: A methodology for performing global uncertainty and sensitivity analysis in systems biology. J Theor Biol 254, 178-196 (2008)

[11] Lloyd, C.M., Lawson, J.R., Hunter, P.J., Nielsen, P.F.: The CellML Model Repository. Bioinformatics 24, 2122-2123 (2008)

[12] Hindmarsh, A.C., Brown, P.N., Grant, K.E., Lee, S.L., Serban, R., Shumaker, D.E., Woodward, C.S.: SUNDIALS: Suite of Nonlinear and Differential/Algebraic Equation Solvers. ACM Transactions on Mathematical Software 31, 33 (2005)

[13] Matsumoto, M., Nishimura, T.: Mersenne twister: a 623-dimensionally equidistributed uniform pseudo-random number generator. ACM Trans. Model. Comput. Simul. 8, 3-30 (1998) [14] Malone, B.P., Minansy, B., Brungard, C.: Some methods to improve the utility of conditioned Latin hypercube sampling. PeerJ 7, e6451 (2019)

[15] Hamby, D.M.: A comparison of sensitivity analysis techniques. Health physics 68, 195-204 (1995)

[16] Shannon, A.G., Hogg, J.M., Ollerton, R.L., Luzio, S., Owens, D.R.: A mathematical model of insulin secretion. IMA journal of mathematics applied in medicine and biology 11, 245-266 (1994)

[17] Critchfield, G.C., Willard, K.E., Connelly, D.P.: Probabilistic sensitivity analysis methods for general decision models. Computers and biomedical research, an international journal 19, 254-265 (1986)

[18] Rahman, A., Matchkov, V., Nilsson, H., Aalkjaer, C.: Effects of cGMP on coordination of vascular smooth muscle cells of rat mesenteric small arteries. Journal of vascular research 42 , 301-311 (2005)

[19] Kharche, S., Yu, J., Lei, M., Zhang, H.: A mathematical model of action potentials of mouse sinoatrial node cells with molecular bases. Am J Physiol Heart Circ Physiol 301, H945-963 (2011)

[20] Kurata, Y., Hisatome, I., Imanishi, S., Shibamoto, T.: Dynamical description of sinoatrial node pacemaking: improved mathematical model for primary pacemaker cell. Am. J. Physiol. Heart. Circ. Physiol. 283, H2074-2101 (2002)

[21] Fabbri, A., Fantini, M., Wilders, R., Severi, S.: Computational analysis of the human sinus node action potential: model development and effects of mutations. J Physiol 595, 2365-2396 (2017)

[22] Krishna, N.A., Pennington, H.M., Coppola, C.D., Eisenberg, M.C., Schugart, R.C.: Connecting Local and Global Sensitivities in a Mathematical Model for Wound Healing. Bulletin of mathematical biology 77, 2294-2324 (2015). 